\title{
Frontal cognitive function and memory in Parkinson's disease: toward a distinction between prospective and declarative memory impairments?
}

\author{
A.I. Tröster and J.A. Fields \\ Department of Neurology, University of Kansas Medical Center, Kansas City, KS, USA \\ Correspondence to: A.I. Tröster, Department of Neurology, University of Kansas Medical \\ Center, 3901 Rainbow Boulevard, Kansas City, KS 66160-7314, USA
}

\begin{abstract}
Memory dysfunction is a frequent concomitant of Parkinson's disease (PD). Historically, two classes of hypotheses, focusing on different cognitive mechanisms, have been advanced to explain this memory impairment: one postulating retrieval deficits (common to several neurodegenerative disorders involving the basal ganglia), and the other postulating frontally mediated executive deficits as fundamental to memory impairment. After outlining empirical support for the retrieval deficit hypothesis, research on the more recent "frontal executive deficit hypothesis" is reviewed, and major challenges to this hypothesis are identified. It is concluded that the frontal executive deficit hypothesis cannot adequately account for all memory impairments in PD, and that a more parsimonious theoretical account might invoke a distinction between prospective and declarative memory impairments. It is suggested that there may be three subgroups of PD patients: one demonstrating prospective memory dysfunction only, one with declarative memory dysfunction only, and one with both prospective and declarative memory dysfunction. Consequently, PD might provide a useful model within which to investigate the relationship between prospective and declarative memory.
\end{abstract}

Keywords: Dementia - Executive functions - Frontal lobes - Memory - Parkinson's disease

\section{INTRODUCTION}

Memory impairments are acknowledged to be among the most common cognitive deficits in Parkinson's disease (PD; Beatty 1992a,b) but the phenomenology, and the cognitive and neural underpinnings of such memory impairments remain poorly understood. Current hypotheses about the cognitive mechanisms underlying PD memory dysfunction fall into two broad categories: one postulating a failure in retrieval operations associated with basal ganglia pathology, and the other postulating an impairment of executive functions (e.g. self-initiated strategic information processing) associated with frontal and/or frontostriatal pathology. Some (e.g. Dubois et al., 1991) see these hypotheses as related, thus proposing that retrieval deficits in PD reflect an executive deficit. However, there is a subtle distinction between the "frontal executive" and "subcortical retrieval" interpretations of PD memory impairment. Whereas the traditional retrieval deficit hypothesis suggests that PD compromises access to stored memories, the frontal hypothesis proposes that the strategies required to initiate and/or maintain efficient

(C) 1995 Rapid Science Publishers retrieval and other cognitive operations are deficient.

One difficulty faced when studying memory in PD is that $\mathrm{PD}$-associated cognitive impairment is rather variable. Indeed, in an attempt to bestow order upon, and understand conflicting empirical findings concerning cognitive impairment in PD, several authors have advocated subgrouping PD on the basis of cognitive impairment patterns. For example, Dubois et al. (1991) proposed that there are three subgroups of PD patients: those with dementia, those with circumscribed cognitive deficits, and those who are cognitively intact. Certainly, most investigators agree that only a subset of PD patients develop dementia, with prevalence estimates ranging from $20 \%$ to $30 \%$ (Mohr et al., 1995). Because much of our understanding of the cognitive and neural mechanisms underlying impaired memory in PD has come from the fruitful application of experimental cognitive psychological paradigms to clinical neuropsychological studies of dementia (see Butters 1984, 1992), a brief historical overview of the rise and decline of the 
"cortical vs subcortical" dementia distinction highlights the evolution of the explanations for memory impairment in PD.

At the outset, it must be stated that this paper concerns itself only with declarative memory, to which the retrieval deficit and executive dysfunction hypotheses are applicable. Readers interested in how neuropsychological studies of PD have informed the distinction between declarative and non-declarative memory (Squire, 1992) are referred to Butters et al. (1990) and Soliveri et al. (1992) for recent reviews.

A brief historical perspective on the "corticalsubcortical" dementia distinction: emergence of the retrieval deficit and executive

dysfunction hypotheses

Dementia was initially thought of as a unitary behavioral syndrome, characterized by a homogeneous decline in intellectual functions, regardless of etiology. Subsequently, programmatic studies of cognition in dementias yielded data suggesting that the pattern of cognitive dysfunction in dementia was heterogeneous, depending largely upon whether the pathological process affected predominantly cortical or subcortical structures. Consequently, a distinction was drawn between "cortical vs subcortical" dementias (Cummings and Benson, 1984). Although the term "subcortical dementia" was first used by Albert et al. (1974) to refer to the cognitive impairment in progressive supranuclear palsy, the term subsequently came to refer to a variety of dementias associated primarily with subcortical pathology early in the course of these diseases [e.g. PD, Huntington's disease (HD) and multiple sclerosis (MS)], which were thought to lead to similar patterns of cognitive impairment.

Generally, the quality of memory impairment in PD parallels that observed in other "subcortical" dementias, but is readily contrasted to the nature of memory impairments in Alzheimer's disease (AD), the prototypical "cortical" dementia. First, PD patients typically demonstrate impaired recall for verbal material such as word lists, prose passages and paired associates, but their recognition of the same material is only slightly, if at all, impaired (Huber et al., 1986a; Helkala et al., 1988; Beatty et al., 1989a; Levin et al., 1989; Mohr et al., 1990; Bondi and Kaszniak, 1991; Pillon et al., 1993; Breen, 1993; Buytenhuijs et al., 1994; Cohen et al., 1994; Tsai et al., 1994). This performance pattern stands in contrast to the impaired recall and recognition observed in AD (Heindel et al., 1993; Pillon et al., 1993; Bondi et al., 1994). Second, PD patients without significant cognitive impairment have relatively normal rates of forgetting, and tend not to commit a large number of intrusion errors (an index of heightened sensitivity to proactive interference). Although PD patients with dementia show more rapid rates of forgetting and commit more intrusion errors than do PD patients without dementia, these abnormalities are still not as pronounced as in AD when the groups' overall severity of dementia is comparable (Beatty et al., 1989b; Kramer et al., 1989; Massman et al., 1990; Pillon et al., 1993; Stern et al., 1993). In addition, whereas the remote memory loss in $\mathrm{AD}$ is characterized by a temporal gradient (with relative preservation of more distant memories), retrograde amnesia in PD, like $\mathrm{HD}$, is equally severe for all past decades (Beatty et al., 1988; Freedman et al., 1984; Huber et al., 1986b, but see Sagar et al., 1988a). Together, these findings have been interpreted as supporting the hypothesis that memory impairment in PD is primarily a function of retrieval deficits, a mechanism thought common to several "subcortical" dementias. That retrieval deficits underlie recall impairments in PD has also been supported by the finding that non-PD patients with focal basal ganglia lesions show impaired recall but intact recognition memory (Dubois et al., 1995). In contrast, memory impairment in "cortical" dementias such as AD is thought to reflect disturbed encoding, consolidation, and storage of memoranda.

Held untenable on neuroanatomical grounds because most dementias eventually compromise both cortical and subcortical structures (Boller et al., 1980; Beatty, 1992a), the distinction between "cortical" and "subcortical" dementia nonetheless persisted and was defended on the basis of its clinical utility (Cummings, 1986, 1988a), and neuropsychological evidence highlighting the heterogeneity of cognitive impairments associated with early "cortical" (AD) and "subcortical" (PD and HD) dementias. More detailed and sophisticated neuropsychological studies of the different dementias, as advocated by Brown and Marsden (1988), have, however, revealed that etiologically distinct "subcortical" dementia cognitive impairment patterns are as dissimilar as they are similar. Thus, although the "cortical-subcortical" distinction may have broad heuristic value (Dubois et al., 1991), several authors have advocated as preferable an investigative strategy relating specific cognitive impairments to specific diseases (Pillon et al., 1991; Heindel et al., 1993). Indeed, research into diseasespecific cognitive impairment has led to the formulation of increasingly refined and detailed hypotheses about the nature of memory impairment in PD, both with and without dementia. Specifically, the notion that retrieval deficits underlie impaired memory in $\mathrm{PD}$, and consequently that there is a primary memory 
impairment in PD, was widely accepted. More recently, some authors have questioned whether memory impairment in PD is a "true" memory impairment. Instead, these authors have proposed that memory impairment is a feature secondary to executive deficits (e.g. an inability to generate efficient strategies demanded by tasks involving self-initiated planning) associated with frontal dysfunction (e.g. Taylor et al., 1990; Pillon et al., 1993).

Albert suggested in 1978 that the term "frontosubcortical" dementia rather than "subcortical" dementia might more appropriately describe cognitive impairments in subcortical diseases, but the possibility that frontal or frontostriatal (as opposed to purely striatal) dysfunction underlies PD memory deficits did not receive serious consideration until this proposal was specifically advanced by Taylor et al. (1986). Given that PD patients have been consistently shown to have a variety of executive deficits (Raskin et al., 1990; Cronin-Golomb et al., 1994; Levin and Katzen, 1995), and given that many cognitive (including memory) tasks "rely on one or more executive components" (Levin and Katzen, 1995), one might accept Taylor et al.'s (1986) proposal as at least face valid. We now turn to review subsequent research into the role of frontal cognitive functions in PD memory impairment which highlights that the issue of the relationship between frontal cognitive and memory functions in PD is considerably more contentious. The debate about the relative merits of the retrieval and executive deficit hypotheses, and about the neural basis of PD memory impairment is unlikely to be resolved soon because, to some extent, this debate parallels the continuing controversy about whether the frontal lobes serve a primary function in memory (see Schacter, 1987; Shimamura et al., 1991; Shimamura, 1994).

\section{STUDIES OF THE ROLE OF FRONTAL COGNITIVE FUNCTIONS IN PD MEMORY IMPAIRMENT}

Recent research into the role of frontally mediated cognitive mechanisms in PD memory impairment can be broadly conceived as following four strategies of investigation: (1) the elucidation of the qualitative nature of memory impairment in PD, and its extant comparison to that reported in studies of patients with frontal lesions; (2) correlation of scores on memory tests and neuropsychological measures purportedly sensitive to frontal dysfunction; (3) the study of PD patients' performance on memory tasks reportedly impacted specifically by frontal dysfunction; and (4) elucidation of the relationship between memory test performance on one hand, and regional cerebral blood flow, glucose metabolism and $\left[{ }^{18} \mathrm{~F}\right]$-dopa uptake determined via functional neuroimaging, on the other hand. Results from studies in each of the above categories are reviewed below.

\section{Qualitative parameters of PD memory impairment}

In their influential paper, Taylor et al. (1986) reported that although their PD sample's memory was "generally intact", deficits were observed on immediate recall of two prose passages, on a spatial delayed recognition task (DRT), and on the Rey Auditory Verbal Learning Test (RAVLT; Rey, 1964), a word list learning and memory test. Taylor et al. (1986) explained impaired immediate but intact delayed recall of the prose passages in terms of slowed information processing (consistent with frontostriatal dysfunction), but intact encoding, storage and retrieval. Although they did not suggest a cognitive mechanism, Taylor et al. (1986) excluded temporal lobemediated mechanisms as accounting for impaired immediate recall on the RAVLT word list by stating that the intact primacy effects observed in PD are not observed in patients with hippocampal damage. Finally, Taylor et al. (1986) found that the nature of the PD group's impairment on the Wisconsin Card Sorting Test (WCST; Heaton, 1981), an executive function test requiring conceptualization of card sorting rules and modification of response strategy to verbal feedback, was typical of that observed in frontal lesion patients. The most parsimonious explanation of the sum of these findings, according to Taylor et al. (1986), is that frontal dysfunction in PD compromises the ability to generate efficient strategies on tasks requiring self-initiated planning.

Several challenges confront Taylor et al.'s (1986) "frontal dysfunction" explanation of PD memory impairment. First, Taylor et al. (1986) correctly pointed out that a normal primacy effect in PD makes it unlikely that temporal lobe dysfunction underlies the PD group's immediate recall impairment on the RAVLT. However, their finding of a normal recency effect is not supportive of the "frontal dysfunction" explanation offered because diminished recency effects have frequently been observed in patients with frontal lesions (see Eslinger and Grattan, 1994). Equally plausible would be the traditional retrieval deficit (associated with basal ganglia pathology) hypothesis given their finding of impaired immediate recall but intact recognition of the word list. Second, Beatty et al. (1989a), although also finding early PD patients to be impaired on the WCST, did not find the errors to be consistent with those made 
by frontal lobe patients. Thus, the possibility is raised that impairments observed by Taylor et al. (1986) on the WCST and memory tasks were related by virtue of their correlation with another variable. Indeed, Taylor et al. (1986) conceded that relationships observed between WCST and RAVLT, and between DRT and RAVLT scores, might be accounted for by correlations between these variables and a third variable (e.g. intelligence or disease severity).

Taylor et al.'s (1986) notion that a frontally mediated impairment in the ability to generate efficient strategies is at the root of PD memory impairments has been supported by several authors' finding that PD patients inefficiently use a semantic clustering strategy during encoding of word lists (Massman et al., 1990; Taylor et al., 1990; Karamat et al., 1991; Buytenhuijs et al., 1994). Whether inefficient semantic encoding is necessarily a consequence of frontal dysfunction is questionable, however. For example, Janowsky et al. (1989a) observed normal release from proactive interference (for which semantic encoding is a prerequisite) in patients with frontal lobe lesions, and Freedman and Cermak (1986) found that semantic encoding was not deficient in all patients with bilateral frontal lobe disease. Furthermore, Beatty et al. (1989b) found that PD patients' poor performance on a semantic verbal fluency test was more related to performance on other measures of semantic memory access than to executive function measures. This raises the possibility that inefficient use of semantic encoding strategies reflects an impairment in semantic memory access rather than a difficulty initiating efficient strategies.

Another challenge to the frontal cognitive dysfunction hypothesis is that executive and memory impairments are dissociable in at least some groups of PD patients. Specifically, PD patients have been observed to have memory impairments in the absence of executive deficits (e.g. Mohr et al., 1990) and executive dysfunction but not declarative memory impairments (Owen et al., 1992). Among unmedicated mild, and medicated mild and moderate PD groups, Owen et al. (1992) found that attentional set-shifting was impaired in all three groups of patients but that none of these groups was impaired on pattern recognition. Furthermore, although the medicated mild PD group in the Owen et al. (1992) study was impaired on a spatial working memory task [a finding contrary to that reported by Morris et al. (1988) using a different form of the task], the group was not impaired on visual pattern or spatial recognition, non-verbal paired associated learning, or immediate and delayed matching to sample tasks. Given Owen et al.'s (1995a) finding that these spatial working memory and spatial recognition tasks are more sensitive to frontal than temporal lobe damage, whereas pattern recognition and delayed matching to sample are more sensitive to temporal damage, it is likely that memory functions mediated by the temporal, but not frontal lobes, are relatively preserved in early PD.

In addition to demonstrating the dissociability of executive and memory impairments in PD, Owen et al. (1992) also observed some important differences in the quality of some of the executive deficits shown by the PD patients and by frontal lesion patients in earlier studies (Owen et al., 1990, 1991). On the Tower of London problem, medicated PD patients demonstrated slowed initial planning time, but normal subsequent thinking time (i.e. time for planning moves after the first move). The converse was observed in frontal lesion patients. In other words, these patients were normal in planning time for the initial move, but slow in planning subsequent moves. Furthermore, the diminished solution accuracy observed in the frontal patients was only noted among more severe PD patients taking medications.

Although studies of the quality of memory impairment in PD may inform about similarities and dissimilarities between memory impairments in PD and frontal patients, a major difficulty of these studies is that they generally fail to establish a relationship between the memory impairment and frontally mediated executive deficits. Obviously, the demonstration of a correlation between memory impairments and other executive deficits would provide stronger evidence that the memory impairment is indeed related to frontal cognitive dysfunction. In pursuit of this aim, several studies have evaluated the relationship between scores on memory tests and neuropsychological tests of "frontal cognitive functions" (e.g. the WCST).

\section{Relationship between performance on} memory and "frontal cognitive function" tasks Bondi et al. (1993) found that the memory and visuospatial test performances of non-demented PD patients no longer differed from those of elderly controls once scores on a series of "frontal lobe tests" [modified WCST (Nelson, 1976), California Sorting Test (Delis et al., 1992), verbal fluency, and a verbal temporal ordering task (after Sagar et al., 1988b)] were covaried. However, the converse was not true. That is, PD patients' performance on the frontal tests was still inferior to that of controls even when memory and visuoperceptual test performance was covaried. Bondi et al. (1993) interpreted these findings as supportive of the frontal dysfunction hypothesis of cognitive impairment in PD. Bondi et al.'s (1993) study is elegant in that it is the only correla- 
tional study to date that has included the critical step of examining both the effects of executive function on memory, and of memory on executive function in PD. Univariate analyses carried out by these authors to supplement multivariate analyses raise an interesting issue, however. Specifically, whereas PD and control groups differed significantly in their performance on each of the four frontal tasks, they differed on only one of four memory tasks. Consequently, the results of the multivariate analyses of covariance are not surprising. If PD and control groups demonstrated little difference in memory to begin with (i.e. PD patients did not have a convincing memory impairment), statistical covariance of frontal measure scores is apt to eliminate this minimal difference.

Cooper and Sagar's (1993) findings might also be interpreted as not particularly supportive of the frontal cognitive dysfunction hypothesis of PD memory impairment. First, Cooper and Sagar (1993) found PD patients to be impaired in the recall of objects but not their spatial locations. Because the frontal lobes are known to have an important role in the processing of spatial context (Grattan and Enslinger, 1991), and because frontal lesion patients have been shown to demonstrate deficits on spatial recognition and working memory tasks (e.g. Owen et al., 1995a), Cooper and Sagar's (1993) finding of intact spatial location recall (together with impaired object recall which might reflect temporal dysfunction) might be taken not to support the executive dysfunction hypothesis of PD memory impairment. Second, in the Cooper and Sagar (1993) study, item recall correlated significantly with only WCST perseverative responses $(r=-0.25)$, but not categories achieved or trials to first category. Thus, even though number of perseverative responses is the WCST index most sensitive to frontal dysfunction, it shared only about $6 \%$ of variance with item recall. Furthermore, item recall correlated significantly with a measure of overall severity of cognitive impairment [Blessed Dementia Scale (BDS; Blessed et al., 1986) score] $(r=-0.53)$, age $(r=-0.40)$, New Adult Reading Test (NART; Nelson and O'Connell, 1978) score $(r=0.28)$, Wechsler Memory Scale (WMS; Wechsler, 1945) Memory Quotient (MQ) $(r=0.65)$ in addition to digit ordering (Cooper et al., 1991) $(r=0.67)$ and Brown-Peterson test (Brown, 1958; Peterson and Peterson, 1959) score $(r=-0.40)$. Because multiple regression analyses were not reported, it is difficult to assess the unique contribution of executive function variables to impaired item recall, but it appears that item recall may be just as, or more strongly related to performance on tests not traditionally considered frontal cognitive function tests.
PD patients' performance on two word list memory tests was found by Pillon et al. (1993) to be highly related to scores on four executive function tests [WCST categories achieved, Dementia Rating Scale (DRS; Mattis, 1988) Initiation/Perseveration scale, semantic verbal fluency, and phonemic verbal fluency] and to a "frontal" score based on behavioral abnormalities. Although supportive of the "frontal hypothesis" of memory dysfunction in PD, several concerns remain. First, the correlation between memory and frontal test scores may reflect the relationship each of these variables bears to a third variable (e.g. severity of overall cognitive impairment). This is suggested by the fact that in Pillon et al.'s (1993) study, memory, executive function and linguistic test scores loaded on one factor accounting for $80 \%$ of the variance. Second, significant correlations between executive function test scores and those memory test scores typically assumed to be sensitive to frontal dysfunction were not reported. For example, for the CVLT, correlations (ranging from 0.54 to 0.77 ) were reported between immediate recall, longdelay cued and free recall, and semantic clustering on the one hand, and WCST, DRS Initiation scale, phonemic fluency, category fluency and "frontal score" on the other hand. No significant correlations were reported between "executive function" scores and CVLT intrusions, perseverations, the contrast between List A and B recall (a measure of proactive interference), and primacy and recency region scores.

Finally, a recent study of the construct validity of the WCST in PD (Paolo et al., 1995) indicates that performance on memory tests such as the Continuous Visual Memory Test (CVMT; Trahan and Larrabee, 1988), the CVLT, and the WMS-R Logical Memory subtest might be relatively independent of WCST performance. Specifically, among both normal elderly and individuals with PD, WCST scores loaded on a factor separate from one on which the memory test scores loaded.

In summary, the studies relating memory and "frontal" test performances provide only weak support for the frontal cognitive dysfunction hypothesis of memory dysfunction in PD. Specifically, modest correlation coefficients between executive and memory test scores indicate that only a small proportion of variance in these scores is shared. Although these studies provide a first step in testing the frontal hypothesis by using rather global measures of memory and executive functions, they do not establish whether a relationship exists in PD between "frontal" test scores and memory variables thought to be specifically related to frontal lobe function. Several studies have been carried out to examine PD 
patients' performance on memory tasks known to be impacted specifically by frontal dysfunction.

\section{Performance of PD patients on "frontal" memory tests}

Several studies employing experimental paradigms indicate that patients with frontal lobe lesions may experience deficits in highly specific aspects of memory. One type of memory in which the frontal lobes appear to play a critical role is that for temporal information (Milner et al., 1985; Hambrecht, 1987; Schacter, 1987; Petrides, 1989). Such deficits in temporal order memory have been suggested as the basic mechanism underlying frontal lobe patients' impairments in recency discrimination (Milner et al., 1985; McAndrews and Milner, 1991; Butters et al., 1994; Eslinger and Grattan, 1994) and source memory (Schacter, 1987). Consequently, several authors seeking to determine whether PD memory impairment is related to frontal dysfunction have examined PD patients' performance on a range of memory tasks sensitive to frontal dysfunction, including recency discrimination, delayed response and alternation, source memory, subject-ordered tasks, and conditional associative learning. Studies of PD using each of these paradigms are reviewed below.

Recency discrimination. Sagar et al. (1988a) found that PD patients' recognition of events in remote memory was relatively intact, but that they had difficulty dating these same events. It is thus possible that poor temporal memory/recency discrimination or sequencing affects PD patients' ability to date, but not to recall, events in remote memory. Sullivan and Sagar (1989) inferred from PD patient's impaired recency discrimination, but intact content recognition of verbal and non-verbal stimuli, that disordered temporal memory also impacts performance on anterograde memory tests. Fischer et al. (1990) also found poor recency recognition in PD. Although these authors ascribed the disordered temporal memory to possible frontal dysfunction, they did not correlate performance on memory and frontal cognitive function tests.

In a subsequent study, Cooper et al. (1993) did report correlations among temporal memory and frontal cognitive function test scores. Specifically, Cooper et al. (1993) investigated temporal memory in PD by examining content recognition and recency discrimination using a modification of Sagar et al.'s (1988b) verbal temporal ordering task. Two of their findings are of particular note. First, although PD patients made more errors on the task overall than did controls, there was no disproportionate impairment in recency discrimination relative to content recognition. On the task as a whole, content recognition correlated only with age, whereas recency discrimination correlated significantly with digit ordering $(r=0.23)$, WCST categories $(r=0.36)$ and BDS $(r=-0.20)$. Second, when recency discrimination was analyzed as a function of stimulus-test interval, an impairment was observed in recency discrimination, but not content recognition, at the shortest stimulus-test interval. Recency judgement at the two shortest intervals in PD correlated significantly with scores on two WCST variables [number of categories $(r=0.29$ to 0.40$)$ and trials to first category $(r=-$ 0.27 to -0.40$)$ ], a digit ordering task $(r=0.33$ to $0.52)$, the Brown-Peterson task ( $r=0.41$ to 0.45$)$, WMS MQ ( $r=0.32$ to 0.47$)$ and BDS $(r=-0.24$ to -0.35$)$. The effect sizes associated with these correlation coefficients are modest, and likely represent overestimates given the probable intercorrelations among measures. Thus, although the findings of Cooper et al. (1993) clearly point to the independence of recency and content recognition, the extent of the association between recency discrimination and frontal cognitive functions is difficult to determine, but likely small.

Delayed response and delayed alternation. Two spatial delayed response tasks apparently are highly sensitive to prefrontal pathology (Freedman and Oscar-Berman, 1986a), and are thought to depend on temporal memory (Oscar-Berman, 1991). Delayed response (DR) tasks involve a reward being placed under one of two or more identical stimuli (in different locations) in full view of the subject. As soon as the stimuli cover the reward, a screen is placed between the subject and the stimuli. Following a brief interval, the screen is raised and the subject has the opportunity to move one of the stimuli. Obviously, if, and only if, the correct choice is made, the subject receives the reward under the stimulus. The DR task thus has a temporal dimension since the subject must delay a response until given the opportunity to respond. The delayed alternation (DA) task is similar to DR in terms of apparatus employed, but different in that the task is both timebased and response-patterned by virtue of the alternation of stimulus-outcome across trials. Whereas damage to the ventral prefrontal system impairs predominantly DA performance, damage to the dorsolateral prefrontal system impairs DR performance (for review see Oscar-Berman, 1991). Bodis-Wollner et al. (1983) found PD patients to be impaired on a DR task, but Freedman and Oscar-Berman (1986b) found only demented PD patients to be impaired on DR. 
Specifically, in a comparison of DR and DA performance among non-demented PD, demented PD and Alzheimer's disease (AD) groups, Freedman and Oscar-Berman (1986b) found demented PD to be impaired on DR only, whereas the AD group was impaired on DR and DA.

That DR might be impaired in only more severely affected PD patients is supported by findings reported by Owen et al. (1993), using a spatial recognition task akin to DR. In this task, subjects are shown during the presentation phase a series of five unfilled white spaces, one at a time, in different locations on a computer screen. In the recognition phase, two spaces appear simultaneously and subjects have to select which of the two locations was used in the presentation phase. Auditory and visual feedback on the (in)correctness of responses is provided after each response. On this task, only PD patients who were medicated and who had severe symptoms were impaired. In sum, the preponderance of findings suggests that delayed response might be sensitive to only more severely affected PD patients' pathophysiology.

Source memory. Another measure thought sensitive to frontal dysfunction (and to depend on temporal memory) is source memory (Janowsky et al., $1989 b)$. Source memory refers to the ability to recall "where and when" information was learned, rather than content. Taylor et al. (1990) attempted to study source memory in early PD using a modification of the California Verbal Learning Test (CVLT; Delis et $a l .$, 1987). Unfortunately, their results were ambiguous, because PD patients were impaired relative to normal controls in identifying the source of words on one list but not another. However, Taylor et al.'s (1990) findings, in combination with those of another recent study (Goldman et al., 1994), indicate the possibility that source memory might be differentially affected in PD and the earliest stages of AD. Whereas Taylor et al. (1990) found suggestive evidence of impaired source memory in PD, Goldman et al. (1994) found that early AD patients, once matched to normal controls for made-up fact recall, performed similarly to the control group on a test of source memory. Together, these findings suggest the potential dissociability of fact and source recall in PD and $\mathrm{AD}$, a finding also reported in amnesics and frontal lesion patients (Janowsky et al., 1989b; Shimamura and Squire, 1987, 1991).

Subject-ordered tasks. The demand common to subject-ordered tasks is the requirement that subjects organize and execute a sequence of responses without the external imposition of a sequence by the experimenter. Such tasks have been shown to be sensitive to frontal dysfunction (e.g. Petrides and Milner, 1982) and medicated PD patients have been shown to be impaired on a subject-ordered pointing task (Gotham et al., 1988). A task akin to subject-ordered tasks is the spatial working memory task employed by Owen et al. $(1990,1992,1995 \mathrm{a})$. In this task, subjects are required to search through boxes presented on a computer screen so as to collect tokens contained in the boxes. At any given time, only one token is hidden in a box, and the subject is instructed to search until that token is found. Once used to hide a token, that box is not used again to hide another token, and subjects are instructed to this effect.

On this task, which has been shown to be particularly sensitive to frontal lobe lesions (Owen et al., $1990,1995 b$ ), both mildly and severely affected, medicated PD patients demonstrate impairments (Owen et al., 1992, 1993). However, the impairment of PD patients and individuals with frontal lesions is qualitatively different. Specifically, the task allows computation of at least two scores: errors (i.e. boxes revisited in which a token was already previously discovered) and strategy. An efficient strategy involves following a predetermined search sequence, and always starting a new search from the same box. Owen et al. (1992) thus quantified strategy by determining the number of searches started from the same and different boxes. Whereas frontal lesion patients performed poorly both in terms of the number of errors and strategy used (Owen et al., 1995b), medicated PD patients made more errors than the normal control subjects, but their strategy use was comparable to that of control subjects (Owen et al., 1992). These findings together again suggest that memory deficits of PD patients may be at least qualitatively different from those observed in frontal lesion groups.

Conditional associative learning. In conditional associative learning tasks, a subject is typically first taught to make a series of responses (e.g. hand gestures). The next step involves the subject learning to which one of several external signals each gesture is appropriate. For example, each of several distinct visual stimuli (e.g. different colored lights) signals that a particular gesture is appropriate. Numerous learning trials are administered, so that if a subject makes an inappropriate response, the subject performs the other possible responses until the correct response is produced to that given stimulus. The usual measure of interest is trials-to-criterion (a predetermined number of consecutive, correct responses). Patients with frontal lesions have been shown to 
have difficulty learning these associations (Petrides, 1985, 1989). PD patients have been noted to also be impaired on conditional associative learning (Gotham et al., 1988; Sahakian et al., 1988; Taylor et al., 1990). However, this effect was only reliably observed in medicated PD patients in the Gotham et al. (1988) and Sahakian et al. (1988) studies, and Canavan et al. (1989a) found early PD patients to perform normally on two conditional associative learning tasks. In addition, memory for hand gesture sequences is apparently impaired in individuals with frontal lesions but not PD (Canavan et al., 1989b).

Summary of issues arising from studies of $P D$ patients' performance on 'frontal" memory tests. Experimental studies of PD patients' performance on "frontal" memory tests perhaps provide the most convincing evidence to date that frontostriatal dysfunction underlies select memory impairments in PD. A major conceptual issue remains, however. Namely, does a frontally related core defect in temporal memory underlie PD patients' impaired performance on all memory tasks? Results of two studies suggest that this might not be the case. A recent study by Parkin and Hunkin (1993) has indicated that frontal pathology may be a necessary condition for impairments in temporal dating of events in remote memory, but that it may not be a necessary condition for impairments in anterograde temporal context memory. This raises the possibility that deficient anterograde and remote temporal memory in PD are mediated by different cognitive and neural mechanisms.

The possibility that different mechanisms underlie impaired temporal ordering and conditional associative learning in PD was suggested in a recent study by Vriezen and Moscovitch (1990). On the temporal ordering task, subjects were required to reproduce from memory a series of stimuli in the order of presentation. Vriezen and Moscovitch (1990) computed indices of the extent to which subjects preserved the absolute and relative order of stimuli. Absolute position was defined as the sum of the distances between the presentation and recall positions of the stimuli. Relative deviation was calculated by summing the distance between 'each stimulus' presentation position and the presentation position of the stimuli placed before and after it on recall". With respect to the temporal ordering task, PD and control subjects did not differ in terms of the number of stimuli placed in the correct position [contrary to Breen's (1993) findings], but PD patients performed more poorly than controls in preserving the relative order of stimuli. Vriezen and Moscovitch (1990) pro- posed that whereas maintenance of the absolute position of stimuli involves relatively automatic processes, recall of the relative position involved more strategic, self-initiated processes. They thus suggest that compromised strategic retrieval processes underlie certain aspects of deficient temporal memory (i.e. relative order). A similar explanation is offered for the finding that PD patients were impaired on conditional association learning when a trial-and-error learning paradigm was used, but not when an immediate feedback paradigm was employed. The authors caution, however, that it is premature to accept that a common mechanism underlies PD patients' impairments on trial-and-error conditional associative learning and recall of relative temporal order, because performances on these two tasks were not strongly correlated. Vriezen and Moscovitch (1990) point out that different regions of the frontal lobes may be critical to the performance of the two tasks, or that the two tasks demand only overlapping (i.e. both shared and unique) cognitive processes.

\section{Functional imaging and memory test performance in $\mathrm{PD}$}

Goldenberg et al. (1989) found non-demented PD patients' impairments in set shifting and attentional control to be related to frontal and parietal blood flow abnormalities on SPECT, but it is unclear if similar pathophysiology and cognitive deficits account for memory impairment. Only two studies have attempted to directly establish a link between brain physiology and memory test performance in PD. Démonet et al. (1994) examined regional cerebral blood flow (rCBF) activation during passive listening and memorization of a word list in 18 early PD patients and 20 normal control subjects. These authors found that different regions were activated in the two subject groups during the listening and memorization tasks. In the control group, memorization was accompanied by increased rCBF in five left-sided regions: anterior middle frontal, posterior inferior frontal, superior middle temporal, thalamic and lenticular. In the PD group, memorization of the word list was associated with activation of only the superior prefrontal regions. Because the PD subjects' recall was comparable to that of the control group, Démonet et al. (1994) interpreted their findings as suggesting the operation in PD of a compensatory memory mechanism supported by the superior prefrontal regions. This raises the possibility that once such a frontally mediated compensatory mechanism fails, PD subjects develop memory dysfunction, although it is also possible (because correlations between $\mathrm{rCBF}$ changes and recall scores were not 
reported) that the frontal activation observed reflects activation of on-line processes important to adequate recall. Similarly, although Holthoff et al. (1994) found impaired verbal memory to be related to PETimaged $\left[{ }^{18} \mathrm{~F}\right]$-dopa uptake reductions in the striatum, the role of possible executive deficits or on-line processes in memory was not investigated.

\section{SOME REMAINING ISSUES ABOUT THE FRONTAL COGNITIVE DYSFUNCTION HYPOTHESIS OF PD MEMORY IMPAIRMENT}

The proposal that PD memory deficits are related to cognitive changes associated with frontal dysfunction is attractive from anatomical and pathological standpoints. First, the striatum and frontal cortex are intimately connected via a series of parallel circuits (Alexander et al., 1986; Cummings, 1993; Mega and Cummings, 1994) and some of these subcortical circuits are in turn connected to regions important to memory, such as entorhinal cortex (Cummings, 1993; Zola-Morgan and Squire, 1993). Consequently, it is plausible that PD striatal pathophysiology has an effect "downstream" on the frontal cortex and on entorhinal cortex and hippocampus. Second, PD might involve pathology of the frontal cortex itself. For example, a reduction of GABAergic receptor density in the frontal cortex of PD patients was reported by Griffiths and Crossman (1992), and reduced frontal cerebral blood flow and oxygen metabolism were observed in PD by Wolfsen et al. (1985). Furthermore, Démonet et al.'s (1994) study indicates that frontal cerebral blood flow may be related to PD patients' performance on a memory task. As plausible as the "frontal cognitive dysfunction" explanation of PD memory deficits may appear from an anatomical standpoint, the empirical neuropsychological evidence attempting to demonstrate the "frontal" nature of PD memory deficits is tenuous.

Perhaps the strongest evidence to date that frontal dysfunction in PD can impair memory comes from studies employing experimental memory tasks specifically sensitive to frontal lesions. This by no means, however, implies that impairments shown by PD patients on standardized memory tests are also attributable to frontal dysfunction. Several factors make it difficult to accept as convincing that all PD memory deficits are exclusively a by-product of executive deficits related to frontal dysfunction. First, there are few direct comparisons of neuropsychological deficits in PD and frontal lesion groups which might provide evidence about the extent to which cognitive deficits in PD resemble those associated with frontal dysfunction. However, even if comparisons among PD and frontal lobe lesion patients' performances on tests of executive functions and memory were forthcoming, they involve several methodological and conceptual difficulties. Methodological concerns regard the comparability of frontal lesion and PD groups on variables which might impact cognition. For example, whereas frontal lesions might be the result of acute and relatively static events (such as cerebrovascular accidents or surgery), $\mathrm{PD}$ is a chronic, progressive disease. Comparability of frontal lesion and PD groups might also be affected by medical regimens of PD patients which can impact frontal cognitive functions and memory in a differential manner (e.g. Lange et al., 1993). Yet another variable on which frontal lesion and PD patients will have to be equated before valid comparisons can be made of the quality of their memory problems, is overall severity of cognitive impairment (see Sagar, 1991); otherwise quantity and quality of impairments are confounded.

One difficulty in relating memory deficits to frontal dysfunction in PD is the fact that the role of the frontal lobes in memory remains debated (Stuss and Benson, 1984; Schacter, 1987; Shimamura et al., 1991). Even when frontal dysfunction is associated with circumscribed memory deficits, the neuropathology and cognitive deficits observed in frontal patient groups are extremely heterogeneous (Stuss et al., 1994), thus making it difficult to establish and describe the mechanisms underlying memory deficits. Given the variability of frontal and PD patients' performances on memory tasks (Beatty, 1992b; Stuss et al., 1994), and given the fact that any one or more of several converging fronto-subcortical circuits might be compromised in PD (Cummings, 1993), one issue confronting researchers is whether one or several cognitive mechanisms underlie PD memory impairment. Certainly, the work of Vriezen and Moscovitch (1990) suggests that different cognitive mechanisms may underlie impaired performance on memory tasks seemingly tapping a similar cognitive mechanism. To this end, it becomes important to identify a measure of memory sensitive to pathology in a large range of frontal regions. Correlation of such a measure with other memory and executive function measures might clarify if a common mechanism underlies memory impairment in PD. Work by Stuss et al. (1994) is of significance in this regard. Specifically, Stuss et al. (1994) found an impairment in subjective clustering of word lists (Sternberg and Tulving, 1977) to be the common thread in the performances of patients with left, right or bilateral lesions in the dorsolateral, medial, septal and striatal frontal regions. That is, frontal lesion patients did not "pair" the same words consistently across recall trials, such that a word 
following another during recall on one trial tended not to follow that same word again on subsequent recall trials. Whether PD patients demonstrate diminished subjective clustering awaits empirical clarification.

In the absence of "frontal" comparison groups, one of the principal investigative strategies has focused on correlating (or covarying) PD patients' performances on memory tests and tests purportedly sensitive to frontal lobe dysfunction, especially the Wisconsin Card Sorting Test (WCST; e.g. Bondi et al., 1993; Pillon et al., 1993). Several methodological and conceptual problems attend such an approach (Beatty, 1992b). One difficulty is that impaired WCST performance is not specific to frontal lobe dysfunction (Heaton, 1981; Anderson et al., 1991), and, given the complexity of the test, likely multidetermined. Indeed, some suggest that no clinical neuropsychological test has been shown to be specifically sensitive to frontal dysfunction (Reitan and Wolfson, 1994). Other obstacles to correlational studies include the observations that the error patterns of PD and frontal patients on the WCST may diverge (Beatty et al., 1989a), and that WCST performance is highly variable across PD samples (Beatty, 1992b).

Even if one were to temporarily suspend these methodological and conceptual objections, the data from correlational studies to date still do not strongly support a frontal cognitive dysfunction explanation of memory impairment in PD. It bears emphasizing that the statistical significance attached to a correlation coefficient merely conveys the probability that the observed relationship between two variables is due to chance or error. With a sufficiently large sample size, even very small correlation coefficients become statistically significant. As Allen and Yen (1979) have pointed out, the most common interpretation of a correlation coefficient is made in terms of its square, which conveys the proportion of the variance in one variable accounted for by its linear relationship with another variable. A survey of the correlation coefficients reported indicates that the variance in memory test scores attributable to frontal cognitive test scores ranges from $4 \%$ to $50 \%$, with the preponderance of values falling into the lower end of this range. Furthermore, these values are likely overestimates given the intercorrelation among variables. This strongly suggests that frontal cognitive functions can impact performance on memory tasks, but that they are unlikely to be the sole or even principal determinants of memory test performance.

The assertion that frontal cognitive dysfunction underlies memory deficits in PD is also confronted by the challenge that frontal cognitive functions and memory may be differentially affected by pharmacological manipulations of the dopaminergic system. Lange et al. (1992, 1993) reported comparisons among PD patients' performances on several frontal cognitive function and memory tasks, both on and off levodopa. Whereas performance on three "frontal" tasks (Tower of London, spatial working memory and attentional set-shifting) was superior on than off levodopa, performance on three tasks with significant declarative memory and lesser working memory demands (pattern and spatial recognition, delayed matching to sample and visuospatial associative learning) was comparable on and off levodopa. Not only do these findings suggest that different neurochemical substrates mediate frontal cognitive functions and memory, but they provide a clear dissociation among these functions, thus suggesting that performance on at least some memory tests can be relatively independent of frontal cognitive functions. Furthermore, not all frontal cognitive functions may be similarly affected by levodopa. For example, Gotham et al. (1988) found that performances on conditional associative learning and subject-ordered pointing were impaired on levodopa, whereas verbal fluency was impaired off levodopa, and WCST performance was impaired both on and off levodopa. Owen et al. (1995b) found that even different measures derived from the same task could be differentially affected by levodopa treatment. Specifically, levodopa-treated PD patients, relative to an unmedicated group, showed better planning accuracy on the Tower of London, but similar (perhaps somewhat larger) latencies. The diversity of empirical findings concerning PD memory impairment suggests that it is important to develop a theoretical framework which accommodates these findings.

\section{TOWARD A DISTINCTION BETWEEN PROSPECTIVE AND DECLARATIVE MEMORY IMPAIRMENT IN PD?}

The distinction between declarative and non-declarative memory (see Squire, 1992) is well accepted, and it has received empirical validation from studies of PD. Another concept, namely prospective memory (Meacham and Leiman, 1982), has only recently begun to receive attention in neuropsychology (see Dalla Barba, 1993). Meacham and Leiman (1982) drew a distinction between retrospective and prospective remembering. Whereas retrospective memory refers to the recollection of information from the past (and most clearly resembles what has been referred to as declarative memory), prospective remembering concerns itself with recalling actions to be 


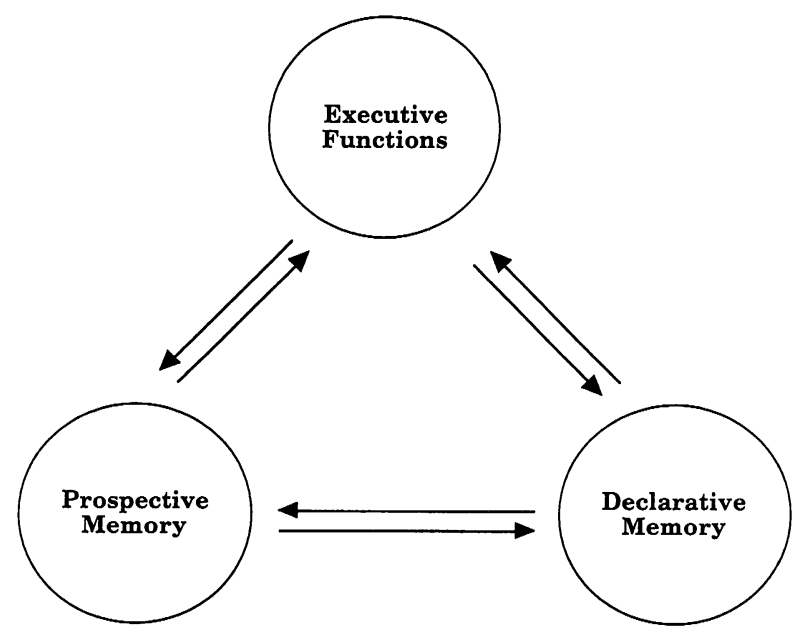

FIG. 1. Simplified representation of the possible interactions among executive, declarative and prospective memory functions.

performed in the future. As Hitch and Ferguson (1991) pointed out, prospective memory can thus be conceptualized as involving the following stages: forming an intention; remembering the intention during an intervening period; and performing the intended action at the appropriate time. Hitch and Ferguson's (1991) study provides a useful exemplar to distinguish prospective and retrospective memory. Retrospective memory might be exemplified by recalling the names of films one has seen in the past. Prospective memory, in contrast, might be exemplified by recalling which films one intends to see in the future and when. One measure of prospective memory, then, might be the person's actual attendance at films intended to be seen. A priori one might expect frontal cognitive functions to play a central role in prospective memory. Prospective memory has a strong temporal component, and we have already reviewed research demonstrating the sensitivity of temporal memory to frontal dysfunction. In addition, prospective memory requires coupling of an action with an intended goal. The role of the frontal lobes in controlling actions by their intended results has been consistently demonstrated (Duncan, 1986). Dalla Barba (1993) has pointed out that prospective memory also requires access to declarative memory or retrospective remembering. A simplified schematic of the potential relationships among executive functions, declarative memory and prospective memory is presented in Fig. 1.

In general, studies with normal subject populations have shown that performances on prospective and retrospective memory tasks are not significantly correlated (Kvavilashvili, 1987; Einstein and McDaniel,
1990; Maylor, 1990; but see Hitch and Ferguson, 1991). The only study investigating prospective memory in dementia (Huppert and Beardsall, 1993) suggests that a similar lack of correlation between prospective and retrospective memory might also be obtained in neurologic populations. It is, however, premature to elevate prospective and declarative memory to the stature of independent memory systems. For one, prior studies generally leave unaddressed the extent to which executive functions, prospective memory and declarative memory are dissociable. In addition, the definitions of executive functions, prospective memory and declarative memory blur. For example, some content of prospective memory, including intentions, can be "declared", and it is unclear if difficulty in some executive functions (e.g. monitoring) can differentially impact prospective and declarative memory, or impact memory but not other domains of cognition. Finally, as Hitch and Ferguson (1991) have pointed out, the apparent lack of correlation between prospective and retrospective memory does not exclude the possibility that similar principles apply in prospective and retrospective memory. Until such issues are more adequately addressed empirically, a simpler distinction may be appropriate.

Shimamura et al. (1991) proposed that the definition of prospective memory might beneficially be expanded to cover "processes and strategies involved in planning, monitoring, and organizing memory, not just actions" (p. 191). If such a definition of prospective memory is accepted, Shimamura et al.'s (1991) review of studies of frontal and amnesic patients makes it clear that prospective and declarative memory can be dissociated in neurologic populations, and that an impairment in one does not necessarily imply an impairment in the other. More specifically, Shimamura et al. (1991) review empirical evidence indicating that individuals with frontal lobe lesions have impaired prospective memory, despite performing normally on what have traditionally been described as declarative memory tasks (i.e. tests of new learning). In contrast, amnesic patients perform well on numerous prospective memory tasks, but fail declarative memory tasks.

Several studies suggest that dissociations between prospective and declarative memory impairments, analogous to those described by Shimamura et al. (1991) among frontal lesion and amnesic patients, might be obtained within PD. Mohr et al. (1990), for example, have described impaired declarative memory in the face of preserved prospective memory, whereas the converse pattern of performance was observed by Owen et al. (1992), at least in the mild PD groups. Indeed, the findings of Sullivan and 
Sagar (1989), Cooper et al. (1993), and data highlighting the dissociability of the effects of pharmacologic manipulation on memory and executive functions (Lange et al., 1993) can also be interpreted as demonstrating a dissociation between prospective and declarative memory impairments. In addition to the two possible subgroups of PD patients showing converse patterns of impairment and preservation of declarative and prospective memory, a likely sizeable third PD subgroup demonstrating impairments in both prospective and declarative memory exists. This can be inferred from the studies demonstrating a relationship (albeit typically a modest one) between performance on frontal cognitive tasks and declarative memory tests. Together, findings of the studies reviewed here point to the possibility that declarative and prospective memory are separable, yet linked.

One possible agenda faced by PD memory research guided by a declarative/prospective memory distinction is the delineation of how executive functions, prospective memory and declarative memory are related. More specifically, research might address which executive functions relate to prospective memory impairment, and whether the same executive functions significantly impact declarative memory. The identification and comparison of processes underlying prospective and declarative memory might be of mutual benefit to neuropsychology and cognitive psychology. Such studies might further the understanding of cognitive mechanisms underlying PD memory impairment, and simultaneously subject to empirical scrutiny the prospective vs declarative memory distinction. If the prospective/declarative memory distinction is empirically supported, the behavioral neurology of PD might be informed by evaluating whether the three PD subgroups defined here on the basis of memory impairments bear any relationship to the three PD subgroups defined by Cummings (1988b) on the basis of different neurotransmitter abnormalities.

We conclude that the prospective/declarative dichotomy provides one framework within which to organize the diverse empirical findings concerning PD memory impairment reviewed here. The framework also permits formulation of a research agenda within which frontal cognitive functions are seen less as an obstacle to understanding PD memory impairment but rather, as Schacter (1987) has advocated, a means of obtaining insights into the nature of normal memory not easily gleaned from the study of pure amnesic patients.

\section{Acknowledgements}

Preparation of this manuscript was supported in part by NIA Grant AG 10182. The authors thank Dr William W.
Beatty and two anonymous reviewers for their insightful and helpful comments on an earlier version of this manuscript.

\section{REFERENCES}

Albert ML (1978) Subcortical dementia. In: Alzheimer's Disease, Senile Dementia and Related Disorders, Vol. 7, Aging (Eds R Katzman, RD Terry and KL Bick), pp. 173-180. Raven Press, New York.

Albert MS, Feldman RG and Willis AL (1974) The "subcortical dementia" of progressive supranuclear palsy. Journal of Neurology, Neurosurgery and Psychiatry, 37, 121130.

Alexander GE, DeLong MR and Strick PL (1986) Parallel organization of functionally segregated circuits linking basal ganglia and cortex. Annual Review of Neuroscience, 9, 357-381.

Allen MJ and Yen WM (1979) Introduction to Measurement Theory. Wadsworth, Belmont.

Anderson SW, Damasio H, Jones RD and Tranel D (1991) Wisconsin Card Sorting Test performance as a measure of frontal lobe damage. Journal of Clinical and Experimental Neuropsychology, 13, 909-922.

Beatty WW (1992a) Memory dysfunction in the subcortical dementias. In: Memory Functioning in Dementia (Ed. L Bäckman), pp. 153-173. Elsevier, Amsterdam.

Beatty WW (1992b) Memory disturbances in Parkinson's disease. In: Parkinson's Disease Neurobehavioral Aspects (Eds SJ Huber and JL Cummings), pp. 49-58. Oxford University Press, New York.

Beatty WW, Salmon DP, Butters N, Heindel WC and Granholm EL (1988) Retrograde amnesia in patients with Alzheimer's disease or Huntington's disease. Neurobiology of Aging, 9, 181-186.

Beatty WW, Staton RD, Weir WS, Monson N and Whitaker HA (1989a) Cognitive disturbances in Parkinson's disease. Journal of Geriatric Psychiatry and Neurology, 2, 22-33.

Beatty WW, Monson N and Goodkin DE (1989b) Access to semantic memory in Parkinson's disease and multiple sclerosis. Journal of Geriatric Psychiatry and Neurology, 2, 153-162.

Blessed G, Tomlinson BE and Roth M (1968) The association between quantitative measures of dementia and of senile changes in cerebral grey matter of elderly subjects. British Journal of Psychiatry, 114, 797-811.

Bodis-Wollner I, Harnois C, Bobak P and Mylin L (1983) On the possible role of temporal delays of afferent processing in Parkinson's disease. Journal of Neural Transmission, 19(Suppl), 243-252.

Boller F, Mitzutani T, Roessman U and Gambetti P (1980) Parkinson's disease, dementia, and Alzheimer's disease: clinicopathological correlation. Annals of Neurology, 1, 329-335.

Bondi MW and Kaszniak AW (1991) Implicit and explicit memory in Alzheimer's disease and Parkinson's disease. Journal of Clinical and Experimental Neuropsychology, 13, 339-358.

Bondi MW, Kaszniak AW, Bayles KA and Vance KT (1993) Contributions of frontal system dysfunction to memory and perceptual abilities in Parkinson's disease. Neuropsychology, 7, 89-102.

Bondi MW, Salmon DP and Butters N (1994) Neuropsycho- 
logical features of memory disorders in Alzheimer's disease. In: Alzheimer Disease (Eds RD Terry, R Katzman, and KL Bick), pp. 41-63. Raven Press, New York.

Breen EK (1993) Recall and recognition memory in Parkinson's disease. Cortex, 29, 91-102.

Brown J (1958) Some tests of the decay theory of immediate memory. Quarterly Journal of Experimental Psychology, 10, 12-21.

Brown RG and Marsden CD (1988) 'Subcortical dementia': the neuropsychological evidence. Neuroscience, 25, 363 387.

Butters MA, Kaszniak AW, Glisky EL, Eslinger PJ and Schacter DL (1994) Recency discrimination deficits in frontal lobe patients. Neuropsychology, 8, 343-353.

Butters N (1984) The clinical aspects of memory disorders: contributions from experimental studies of amnesia and dementia. Journal of Clinical Neuropsychology, 6, 17-36.

Butters N (1992) Memory remembered: 1970-1991. Archives of Clinical Neuropsychology, 7, 285-295.

Butters N, Heindel WC and Salmon DP (1990) Dissociation of implicit memory in dementia: neurological implications. Bulletin of the Psychonomic Society, 28, 359366.

Buytenhuijs EL, Berger HJC, Van Spaendonck KPM, Horstink WIM, Borm GF and Cools AR (1994) Memory and learning strategies in patients with Parkinson's disease. Neuropsychologia, 32, 335-342.

Canavan AGM, Passingham RE, Marsden CD, Quinn N, Wyke $M$ and Polkey CE (1989a) The performance on learning tasks of patients in the early stages of Parkinson's disease. Neuropsychologia, 27, 141-156.

Canavan AGM, Passingham RE, Marsden CD, Quinn N, Wyke M and Polkey CE (1989b) Sequencing ability in Parkinsonians, patients with frontal lobe lesions, and patients who have undergone unilateral temporal lobectomies. Neuropsychologia, 27, 787-798.

Cohen H, Bouchard S, Scherzer P and Whitaker H (1994) Language and verbal reasoning in Parkinson's disease. Neuropsychiatry, Neuropsychology and Behavioral Neurology, 7, 166-175.

Cooper JA and Sagar HJ (1993) Incidental and intentional recall in Parkinson's disease: an account based on diminished attentional resources. Journal of Clinical and Experimental Neuropsychology, 15, 713-731.

Cooper JA, Sagar HJ, Jordan N, Harvey NS and Sullivan EV (1991) Cognitive impairment in early, untreated Parkinson's disease and its relationship to motor disability. Brain, 114, 2095-2122.

Cooper JA, Sagar HJ and Sullivan EV (1993) Short-term memory and temporal ordering in early Parkinson's disease: effects of disease chronicity and medication. Neuropsychologia, 31, 933-949.

Cronin-Golomb A, Corkin S and Growdon JH (1994) Impaired problem solving in Parkinson's disease: impact of a set-shifting deficit. Neuropsychologia, 32, 579-593.

Cummings JL (1986) Subcortical dementia: neuropsychology, neuropsychiatry, and pathophysiology. British Journal of Psychiatry, 149, 682-697.

Cummings JL (1988a) Intellectual impairment in Parkinson's disease: clinical, pathologic, and biochemical correlates. Journal of Geriatric Psychiatry and Neurology, 1, 24-36.

Cummings JL (1988b) The dementias of Parkinson's disease: prevalence, characteristics, neurobiology, and com- parison with dementia of the Alzheimer type. European Neurology, 28(suppl 1), 15-23.

Cummings JL (1993) Frontal-subcortical circuits and human behavior. Archives of Neurology, 50, 873-880.

Cummings JL and Benson DF (1984) Subcortical dementia: review of an emerging concept. Archives of Neurology, 41, 874-879.

Dalla Barba G (1993) Prospective memory: a "new" memory system? In: Handbook of Neuropsychology, Vol. 8 (Eds F Boller and J Grafman), pp. 239-251. Elsevier, Amsterdam.

Delis DC, Kramer JH, Kaplan E and Ober BA (1987) California Verbal Learning Test. The Psychological Corporation, New York.

Delis DC, Squire LR, Bihrle A and Massman P (1992) Componential analysis of problem solving ability: performance of patients with frontal lobe damage and amnesic patients on a new sorting test. Neuropsychologia, 30, 683-698.

Démonet J-F, Celsis P, Agniel A, Cardebat D, Rascol O and Marc-Vergnes J-P (1994) Activation of regional cerebral blood flow by a memorization task in early Parkinson's disease patients and normal subjects. Journal of Cerebral Blood Flow and Metabolism, 14, 431-438.

Dubois B, Boller F, Pillon B and Agid Y (1991) Cognitive deficits in Parkinson's disease. In: Handbook of Neuropsychology, Vol. 5 (Eds F Boller and J Grafman), pp. 195240. Elsevier, Amsterdam.

Dubois B, Defontaines B, Deweer B, Malapani C and Pillon B (1995) Cognitive and behavioral changes in patients with focal lesions of the basal ganglia. In: Behavioral Neurology of Movement Disorders, Advances in Neurology, Vol. 65 (Eds WJ Weiner and AE Lang), pp. 2941. Raven Press, New York.

Duncan J (1986) Disorganization of behaviour after frontal lobe damage. Cognitive Neuropsychology, 3, 271-290.

Einstein GO and McDaniel MA (1990) Normal aging and prospective memory. Journal of Experimental Psychology: Learning, Memory and Cognition, 16, 717-726.

Eslinger PJ and Grattan LM (1994) Altered serial position learning after frontal lobe lesion. Neuropsychologia, 32, 729-739.

Fischer P, Kendler P and Goldenberg G (1990) Recencyprimacy recognition in Parkinson's disease. Journal of Neural Transmission, 32, 71-77.

Freedman M and Cermak LS (1986) Semantic encoding deficits in frontal lobe disease and amnesia. Brain and Cognition, 5, 108-114.

Freedman M and Oscar-Berman M (1986a) Bilateral frontal lobe disease and selective delayed response deficits in humans. Behavioral Neuroscience, 100, 337-342.

Freedman M and Oscar-Berman M (1986b) Selective delayed response deficits in Parkinson's and Alzheimer's disease. Archives of Neurology, 43, 886-890.

Freedman M, Rivoira P, Butters N, Sax DS and Feldman RS (1984) Retrograde amnesia in Parkinson's disease. Canadian Journal of Neurological Sciences, 11, 297-301.

Goldenberg G, Podreka I, Müller C and Deecke L (1989) The relationship between cognitive deficits and frontal lobe function in patients with Parkinson's disease: an emission computerized tomography study. Behavioural Neurology, 2, 79-87.

Goldman WP, Winograd E, Goldstein FC, O'Jile $\mathbf{J}$ and Green RC (1994) Source memory in mild to moderate 
Alzheimer's disease. Journal of Clinical and Experimental Neuropsychology, 16, 105-116.

Gotham AM, Brown RG and Marsden CD (1988) "Frontal" cognitive function in patients with Parkinson's disease "on" and "off" levodopa. Brain, 111, 299-321.

Grattan LM and Eslinger PJ (1991) Frontal lobe damage in children and adults: a comparative review. Developmental Neuropsychology, 7, 283-326.

Griffiths PD and Crossman AR (1992) Receptor changes in the neocortex of post-mortem tissue in Parkinson's disease and Alzheimer's disease. Dementia, 3, 239246.

Hambrecht M (1987) Gedächtnisstörungen bei Frontalhirnläsionen [Memory deficits in patients with frontal lobe lesions]. Nervenarzt, 58, 131-136.

Heaton RK (1981) Wisconsin Card Sorting Test Manual. Psychological Assessment Resources, Odessa, FL.

Heindel WC, Salmon DP and Butters N (1993) Cognitive approaches to the memory disorders of demented patients. In: Comprehensive Handbook of Psychopathology, 2nd edn (Eds PB Sutker and HE Adams), pp. 735-761. Plenum Press, New York.

Helkala E-L, Laulumaa V, Soininen $\mathrm{H}$ and Riekkinen PJ (1988) Recall and recognition memory in patients with Alzheimer's and Parkinson's diseases. Annals of Neurology, 24, 214-217.

Hitch GJ and Ferguson J (1991) Prospective memory for future intentions: some comparisons with memory for past events. European Journal of Cognitive Psychology, 3, 285-295.

Holthoff VA, Vieregge P, Kessler J, Pietrzyk V, Herholz $\mathrm{K}$, Bonner J, Wagner R, Wienhard $\mathrm{K}$, Pawlik $\mathrm{G}$ and Heiss W-D (1994) Discordant twins with Parkinson's disease: positron emission tomography and early signs of impaired cognitive circuits. Annals of Neurology, 36, 176182.

Huber SJ, Shuttleworth EC, Paulson GW, Bellchambers MJG, and Clapp LE (1986a) Cortical vs. subcortical dementia. Neuropsychological differences. Archives of Neurology, 43, 392-394.

Huber SJ, Shuttleworth EC and Paulson GW (1986b) Dementia in Parkinson's disease. Archives of Neurology, 43, 987-990.

Huppert FA and Beardsall L (1993) Prospective memory impairment as an early indicator of dementia. Journal of Clinical and Experimental Neuropsychology, 15, 805-821.

Janowsky JS, Shimamura AP, Kritchevsky M and Squire LR (1989a) Cognitive impairment following frontal lobe damage and its relevance to human amnesia. Behavioral Neuroscience, 103, 548-560.

Janowsky JS, Shimamura AP and Squire LR (1989b) Source memory impairment in patients with frontal lobe lesions. Neuropsychologia, 27, 1043-1056.

Karamat E, IImberger J, Poewe W. and Gerstenbrand F (1991) Memory dysfunction in Parkinson patients: an analysis of verbal learning processes. Journal of Neural Transmission, 33(Suppl), 93-97.

Kramer JH, Levin BE, Brandt J and Delis DC (1989) Differentiation of Alzheimer's, Huntington's, and Parkinson's disease patients on the basis of verbal learning characteristics. Neuropsychology, 3, 111-120.

Kvavilashvili L (1987) Remembering intention as a distinct form of memory. British Journal of Psychology, 78, 507518.
Lange KW, Robbins TW, Marsden CD, James M, Owen AM and Paul GM (1992) L-Dopa withdrawal in Parkinson's disease selectively impairs cognitive performance tests sensitive to frontal lobe dysfunction. Psychopharmacology, 107, 394-404.

Lange KW, Paul GM, Robbins TW and Marsden CD (1993) L-DOPA and frontal cognitive function in Parkinson's disease. In: Parkinson's Disease: From Basic Research to Treatment, Advances in Neurology, Vol. 60 (Eds $\mathrm{H}$ Narabayashi, T Nagatsu, N Yanagisawa and $\mathrm{Y}$ Mizuno), pp. 475-478. Raven Press, New York.

Levin BE and Katzen HL (1995) Early cognitive changes and nondementing behavioral abnormalities in Parkinson's disease. In: Behavioral Neurology of Movement Disorders, Advances in Neurology, Vol. 65 (Eds WJ Weiner and AE Lang), pp. 85-95. Raven Press, New York.

Levin BE, Llabre MM and Weiner WJ (1989) Cognitive impairments associated with early Parkinson's disease. Neurology, 39, 557-561.

Massman PJ, Delis DC, Butters N, Levin BE and Salmon DP (1990) Are all subcortical dementias alike?: verbal learning and memory in Parkinson's and Huntington's disease patients. Journal of Clinical and Experimental Neuropsychology, 12, 729-744.

Mattis S (1988) Dementia Rating Scale. Psychological Assessment Resources, Odessa, FL.

Maylor EA (1990) Age and prospective memory. Quarterly Journal of Experimental Psychology, 42A, 471-494.

McAndrews MP and Milner B (1991) The frontal cortex and memory for temporal order. Neuropsychologia, 29, 849-859.

Meacham JA and Leiman B (1982) Remembering to perform future actions. In: Memory Observed: Remembering in Natural Contexts (Ed. U Neisser), pp. 327-336. WH Freeman, San Francisco.

Mega MS and Cummings JL (1994) Frontal-subcortical circuits and neuropsychiatric disorders. Journal of Neuropsychiatry and Clinical Neurosciences, 6, 358-370.

Milner B, Petrides M and Smith ML (1985) Frontal lobes and the temporal organization of memory. Human Neurobiology, 4, 137-142.

Mohr E, Juncos J, Cox C, Litvan I, Fedio P and Chase TN (1990) Selective deficits in cognition and memory in high-functioning Parkinsonian patients. Journal of Neurology, Neurosurgery and Psychiatry, 53, 603-606.

Mohr E, Mendis T and Grimes JD (1995) Late cognitive changes in Parkinson's disease with an emphasis on dementia. In: Behavioral Neurology of Movement Disorders, Advances in Neurology, Vol. 65 (Eds WJ Weiner and AE Lang), pp. 97-113. Raven Press, New York.

Morris RG, Downes JJ, Sahakian BJ, Evende JL, Heald A and Robbins TW (1988) Planning and spatial working memory in Parkinson's disease. Journal of Neurology, Neurosurgery and Psychiatry, 51, 757-766.

Nelson HE (1976) A modified card sorting test sensitive to frontal lobe defects. Cortex, 12, 313-324.

Nelson HE and O'Connell A (1978) Dementia: the estimation of premorbid intelligence levels using the New Adult Reading Test. Cortex, 14, 234-244.

Oscar-Berman M (1991) Clinical and experimental approaches to varieties of memory. International Journal of Neuroscience, 58, 135-150. 
Owen AM, Downes JD, Sahakian BJ, Polkey CE and Robbins TW (1990) Planning and spatial working memory following frontal lobe lesions in man. Neuropsychologia, 28, 1021-1034.

Owen AM, Roberts AC, Polkey CE, Sahakian BJ and Robbins TW (1991) Extra-dimensional versus intradimensional set shifting performance following frontal lobe excisions, temporal lobe excisions, or amygdalohippocampectomy in man. Neuropsychologia, 29, 9931006.

Owen AM, James M, Leigh PN, Summers BA, Marsden CD, Quinn NP, Lange KW and Robbins TW (1992) Fronto-striatal cognitive deficits at different stages of Parkinson's disease. Brain, 115, 1727-1751.

Owen AM, Sahakian BJ, Semple J, Polkey CE and Robbins TW (1995a) Visuo-spatial short-term recognition memory and learning after temporal lobe excisions, frontal lobe excisions or amygdalo-hippocampectomy in man. Neuropsychologia, 33, 1-24.

Owen AM, Sahakian BJ, Hodges JR, Summers BA, Polkey CE and Robbins TW (1995b) Dopamine-dependent frontrostriatal planning deficits in early Parkinson's disease. Neuropsychology, 9, 126-140.

Paolo AM, Tröster AL, Axelrod BN and Koller WC (1995) Construct validity of the WCST in normal elderly and persons with Parkinson's disease. Archives of Clinical Neuropsychology, in press.

Parkin AJ and Hunkin NM (1993) Impaired temporal context memory on anterograde but not retrograde tests in the absence of frontal pathology. Cortex, 29, 267280.

Peterson LR and Peterson MJ (1959) Short-term retention of individual items. Journal of Experimental Psychology, 58, 193-198.

Petrides M (1985) Deficits on conditional associative-learning tasks after frontal- and temporal-lobe lesions in man. Neuropsychologia, 23, 601-614.

Petrides M (1989) Frontal lobes and memory. In: Handbook of Neuropsychology, Vol. 3 (Eds F Boller and J Grafman), pp. 75-90. Elsevier, Amsterdam.

Petrides M and Milner B (1982) Deficits on subject-ordered tasks after frontal- and temporal-lobe lesions in man. Neuropsychologia, 20, 249-262.

Pillon B, Dubois B, Ploska A and Agid Y (1991) Severity and specificity of cognitive impairment in Alzheimer's, Huntington's, Parkinson's diseases and progressive supranuclear palsy. Neurology, 41, 634-543.

Pillon B, Deweer B, Agid Y and Dubois B (1993) Explicit memory in Alzheimer's, Huntington's and Parkinson's diseases. Archives of Neurology, 50, 374-379.

Raskin SA, Borod JC and Tweedy J (1990) Neuropsychological aspects of Parkinson's disease. Neuropsychology Review, 1, 185-221.

Reitan RM and Wolfson D (1994) A selective and critical review of neuropsychological deficits and the frontal lobes. Neuropsychology Review, 4, 161-198.

Rey A (1964) L'Examen clinique en psychologie. Presses Universitaires de France, Paris.

Sagar HJ (1991) Specificity of cognitive impairment in neurological disease: a methodological critique of Parkinson's disease. Behavioural Neurology, 4, 89-102.

Sagar HJ, Cohen NJ, Sullivan EV, Corkin S and Growdon JH (1988a) Remote memory function in Alzheimer's disease and Parkinson's disease. Brain, 111, 185-206.
Sagar HJ, Sullivan EV, Gabrieli JDE, Corkin S and Growdon JH (1988b) Temporal ordering and short-term memory deficits in Parkinson's disease. Brain, 111, 525539

Sahakian BJ, Morris RG, Evenden JL, Heald A, Levy R, Philpot M and Robbins TW (1988) A comparative study of visuospatial memory and learning in Alzheimertype dementia and Parkinson's disease. Brain, 111, 695718

Schacter DL (1987) Memory, amnesia, and frontal lobe dysfunction. Psychobiology, 15, 21-36.

Shimamura AP (1994) Memory and frontal lobe function. In: The Cognitive Neurosciences (Ed. MS Gazzaniga), pp. 803-813. MIT Press, Cambridge, MA.

Shimamura AP and Squire LR (1987) A neuropsychological study of fact memory and source amnesia. Journal of Experimental Psychology: Learning, Memory, and Cognition, 13, 464-473.

Shimamura AP and Squire LR (1991) The relationship between fact and source memory: findings from amnesic patients and normal subjects. Psychobiology, 19, 1-10.

Shimamura AP, Janowsky JS and Squire LR (1991) What is the role of frontal lobe damage in memory disorders? In: Frontal Lobe Function and Dysfunction (Eds HS Levin, HM Eisenberg and AL Benton), pp. 173-195. Oxford University Press, New York.

Soliveri P, Brown RG, Jahanshahi $M$ and Marsden CD (1992) Procedural memory and neurological disease. European Journal of Cognitive Psychology, 4, 161-193.

Squire LR (1992) Declarative and nondeclarative memory: multiple brain systems supporting learning and memory. Journal of Cognitive Neuroscience, 4, 232-243.

Stern Y, Richards M, Sano M and Mayeux R (1993) Comparison of cognitive changes in patients with Alzheimer's and Parkinson's disease. Archives of Neurology, 50, $1040-1045$

Sternberg RJ and Tulving E (1977) The measurement of subjective organization in free recall. Psychological Bulletin, 84, 539-556.

Stuss DT and Benson DF (1984) Neuropsychological studies of the frontal lobe. Psychological Bulletin, 95, 328.

Stuss DT, Alexander MP, Palumbo CL, Buckle L, Sayer L and Pogue J (1994) Organizational strategies of patients with unilateral or bilateral frontal lobe injury in word list learning tasks. Neuropsychology, 8, 355-373.

Sullivan EV and Sagar HJ (1989) Nonverbal recognition and recency discrimination deficits in Parkinson's disease and Alzheimer's disease. Brain, 112, 1503-1517.

Taylor AE, Saint-Cyr JA and Lang AE (1986) Frontal lobe dysfunction in Parkinson's disease: the cortical focus of neostriatal outflow. Brain, 109, 845-883.

Taylor AE, Saint-Cyr JA and Lang AE (1990) Memory and learning in early Parkinson's disease: evidence for a "frontal lobe syndrome". Brain and Cognition, 13, 211232

Trahan DE and Larrabee GJ (1988) Continuous Visual Memory Test: Professional Manual. Psychological Assessment Resources, Odessa, FL.

Tsai C-H, Lu C-S, Hua M-S, Lo W-L and Lo S-K (1994) Cognitive dysfunction in early onset parkinsonism. Acta Neurologica Scandinavica, 89, 9-14.

Vriezen ER and Moscovitch M (1990) Memory for temporal order and conditional associative-learning in patients 
with Parkinson's disease. Neuropsychologia, 28, 12831293.

Wechsler D (1945) A standardized memory scale for clinical use. Journal of Psychology, 19, 87-95.

Wolfsen LI, Leenders KL, Brown LC and Jones T (1985) Alterations in regional cerebral blood flow and oxygen metabolism in Parkinson's disease. Neurology, 35, 15061510 .
Zola-Morgan S and Squire LR (1993) Neuroanatomy of memory. Annual Review of Neurosciences, 16, 547-563.

(Received 8 February 1995; accepted as revised 13 July 1995) 


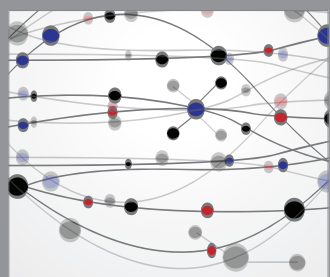

The Scientific World Journal
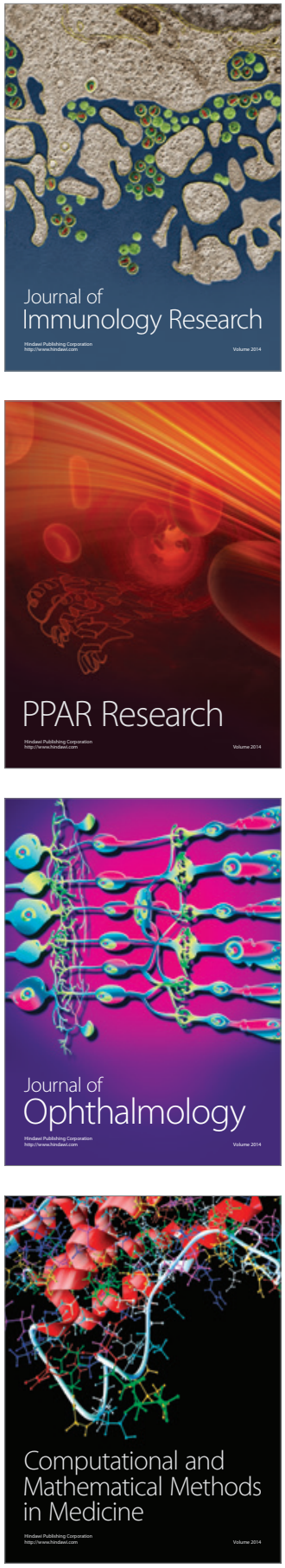

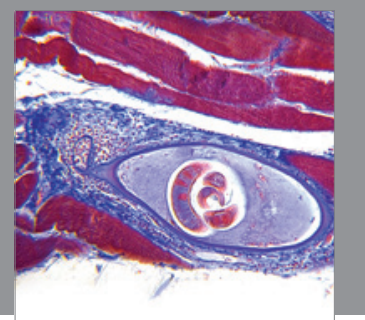

Gastroenterology

Research and Practice
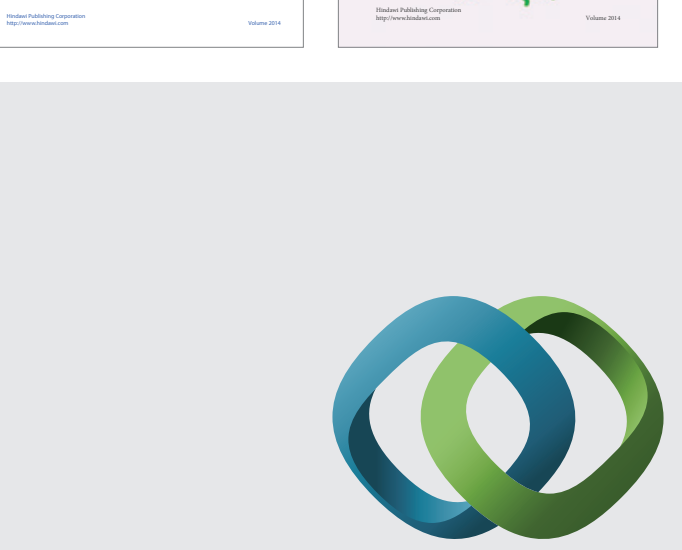

\section{Hindawi}

Submit your manuscripts at

http://www.hindawi.com
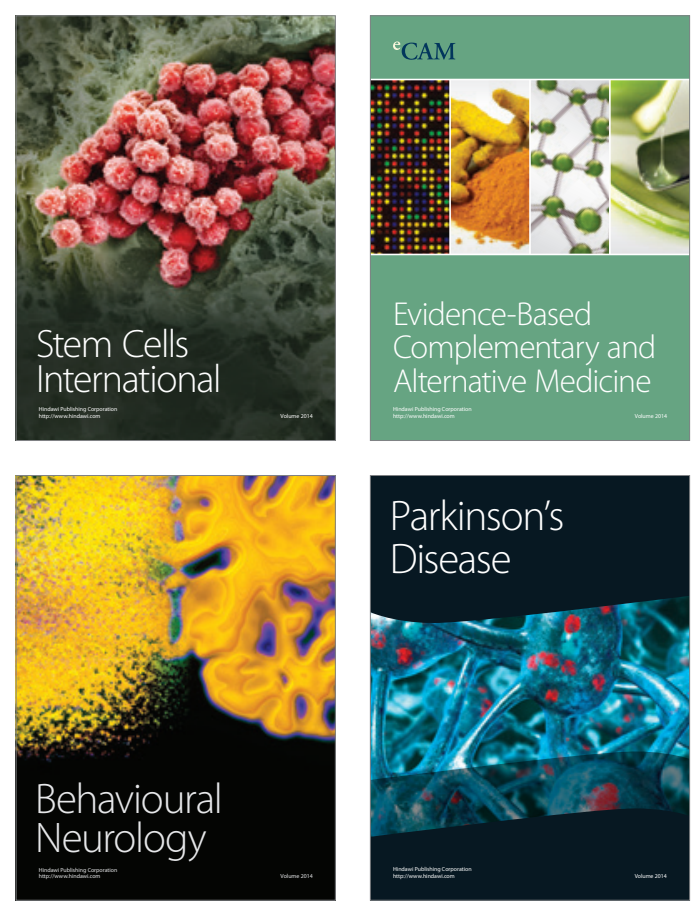

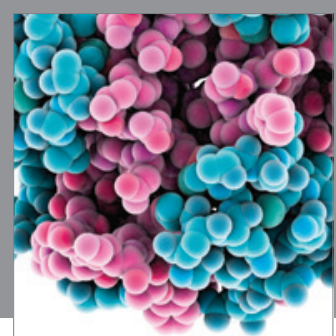

Journal of
Diabetes Research

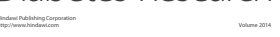

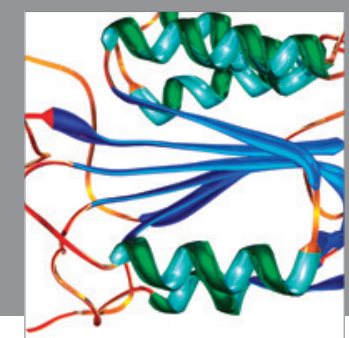

Disease Markers
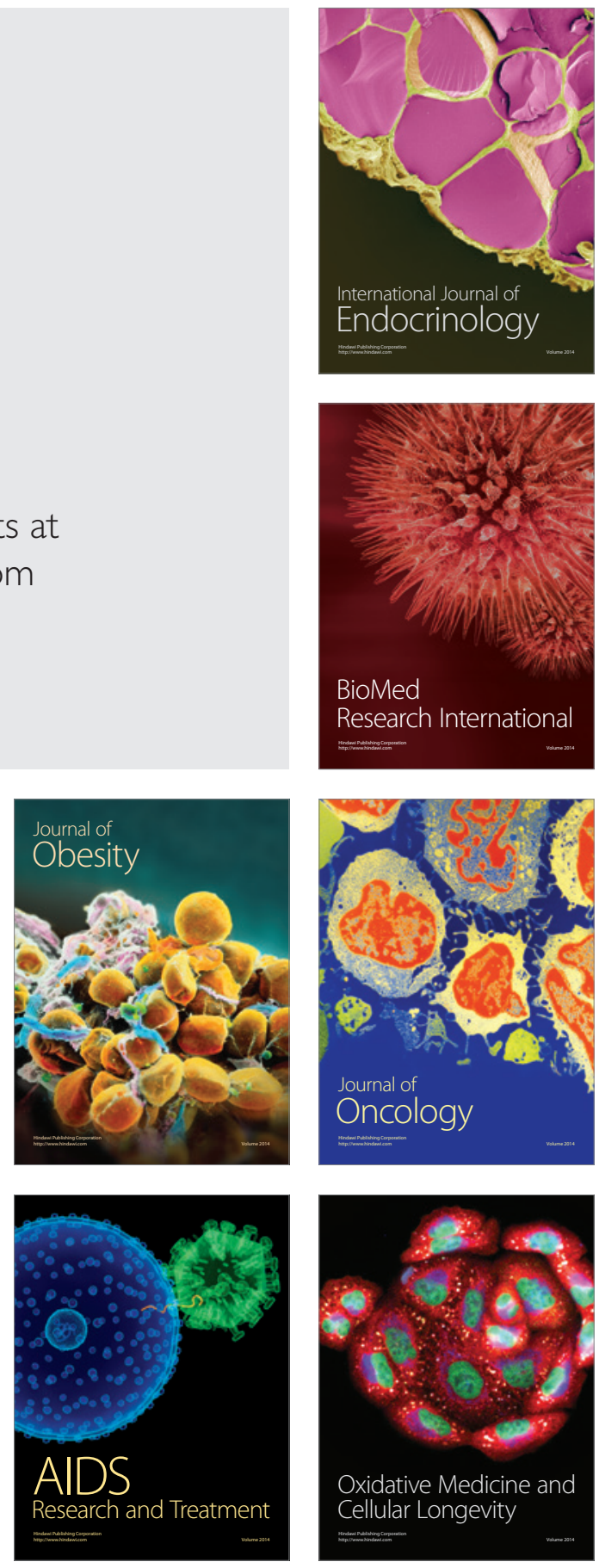